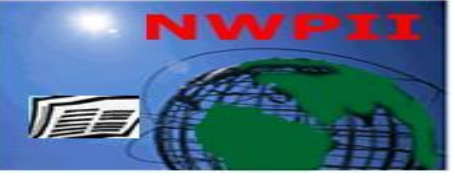

American Journal of Biomedical Sciences

ISSN: 1937-9080

nwpii.com/ajbms

\title{
Detection of the NQO1 C609T polymorphism by a simple one step Tri- primer Amplification Refractory Mutation System-PCR method
}

\author{
Bassam Lajin $^{1 *}$, Amal Alachkar ${ }^{2}$ \\ ${ }^{1}$ Department of Analytical Chemistry, Faculty of Pharmacy, University of Aleppo, Aleppo, Syria \\ ${ }^{2}$ Department of Pharmacology, Faculty of Pharmacy, University of Aleppo, Aleppo, Syria \\ *Corresponding Author \\ Bassam Lajin \\ Research Associate \\ Faculty of Pharmacy, \\ University of Aleppo, Aleppo, Syria \\ Email: Bassam17@yahoo.co.uk
}

Received: 24 December 2010; $\mid$ Revised: 26 January 2011; $\mid$ Accepted: 15 February 2011

\begin{abstract}
$\mathrm{NAD}(\mathrm{P}) \mathrm{H}$ :quinone oxidoreductase 1 (NQO1) is an enzyme with antioxidant functions. It catalyzes the two-electron reduction of quinones and nitrogen-oxides, reducing the formation of reactive oxygen species by decreasing one-electron reductions. A common polymorphism in the NQO1 gene involves the substitution of cytosine with thymine $(609 \mathrm{C} \rightarrow \mathrm{T})$, giving rise to a proline to serine substitution, which decreases NQO1 enzymatic activity. The C609T polymorphism was shown to be important in a broad range of biomedical fields, especially cancer research. In this paper, we describe a new method for the detection of C609T based on the Amplification Refractory Mutation System - Polymerase Chain Reaction method (ARMS-PCR). Two specific forward primers differing in length and in the $3^{\prime}$ base, and one common reverse primer were combined in a single PCR reaction. Genotype adscription was based on the amplification of either one or both of two specific amplicons (75 bp for the $\mathrm{C}$ allele and $90 \mathrm{bp}$ for the $\mathrm{T}$ allele) as shown following agarose gel electrophoresis. The method was validated using a PCR-RFLP method. The proposed method was used to characterize the genotype distribution of the C609T polymorphism in a sample population from Aleppo, Syria, where $2.8 \%$ of the sample population were found to be homozygous for the $\mathrm{T}$ allele, and $78.8 \%$ were found to be homozygous for the $\mathrm{C}$ allele.
\end{abstract}

Keywords: NQO1; C609T; single nucleotide polymorphism (SNP); Pro187Ser; RFLP; Amplification refractory mutation system.

\section{Introduction}

NQO1, also referred to as DT-diaphorase, is a 274-amino acid protein that catalyzes a two-

Am. J. Biomed. Sci. 2011, 3(2), 77-83; doi: 10.5099/aj110200077 electron reduction of various quinones including their respective quinonoid derivatives into stable non-toxic hydroquinones. NQO1 is the dominant intracellular two-electron transfer quinone reductase. The enzymatic activity of that protein

(c) 2011 by NWPII. All rights reserved. 
blocks the one electron reduction of quinones that causes the formation of radical species. The human representative $N Q O 1$ gene is located on chromosome 16q22. The replacement of cytosine with thymine $(609 \mathrm{C} \rightarrow \mathrm{T})$ is accompanied by a proline to serine substitution, which decreases the NQO1 enzymatic activity [1-3]. NQO1 genotypes from the $\mathrm{C} 609 \mathrm{~T}$ polymorphism were classified as wild-type $(\mathrm{C} / \mathrm{C})$, heterozygous genotype $(\mathrm{C} / \mathrm{T})$, and homozygous genotype (T/T).

NQO1 was found to play an important role in apoptosis and oxidative stress, and the effects of C609T were thoroughly investigated in several types of cancers [4-8], and neurologic disorders [9-11], with positive association being found in several reports. The C609T polymorphism was confirmed to play an important role in the susceptibility to chronic benzene poisoning among industrial workers, with TT homozygotes having greatly elevated risk [12-15]. The polymorphism was also recently investigated with respect to the effects of air pollution [16].

Several methods were reported for the detection of C609T with PCR-RFLP as the most common method [17 -19]. PCR-CTPP and the TaqMan method were also utilized [10,20,21].

The aim of the present work was to develop a simple, rapid, and cost-effective method for the detection of NQO1 C609T polymorphism that overcomes several disadvantages associated with the commonly used methods, such as low detection throughput and high cost.

\section{Methods and Materials}

\subsection{Subjects}

The population studied consisted of 71 white healthy unrelated subjects living in Aleppo, Syria
(40 males, 31 females, Mean age $41 \pm 10$ ). All subjects were native Syrians and of the same ethnicity (Arabs). Informed consent was obtained from each subject. Blood samples were collected in EDTA tubes and anonymously coded and stored.

\subsection{DNA isolation}

Genomic DNA was isolated from $200 \mu \mathrm{l}$ venous blood using a spin column format kit (EuroGold $^{\mathrm{TM}}$ Blood DNA mini kit, Euroclone, Italy). The procedure was carried out according to the manufacturer instructions.

\subsection{Quantification of genomic DNA}

Quantification of DNA was performed using V-650 UV-VIS spectrophotometer (Jasco, Japan). A260/A280 ratios were in the range of 1.8-1.9 indicating high purity genomic DNA extract. Extraction yield was in the range of $4-8 \mu \mathrm{g} / 200 \mu \mathrm{l}$ blood.

\subsection{Tri-primer ARMS-PCR analysis}

Three primers were used in a single PCR reaction (Fig. 1a). Two specific forward primers, $\mathrm{P} 1$ and P2 (Table 1), differing in length, were designed with complementary 3 '- terminal nucleotide to the corresponding polymorphism. A common reverse primer $\mathrm{P} 3$ is used to amplify a 75 bp $\mathrm{C}$ allele-specific fragment or $90 \mathrm{bp} \mathrm{T}$ allelespecific fragment with $\mathrm{P} 1$ or $\mathrm{P} 2$, respectively. To enhance specificity, a destabilizing mismatch was incorporated at the $3^{\text {rd }}$ nucleotide from the $3^{\prime}$ terminus in each specific primer. A mismatch at the terminal 5' nucleotide of the short specific primer was introduced in order to minimize megapriming.

Table 1 Primers used in C609T NQO1 analysis by Tri-primer ARMS-PCR.

\begin{tabular}{ll}
\hline Primer & Sequence $\left(\mathbf{5}^{\prime} \rightarrow \mathbf{3}^{\prime}\right)$ \\
\hline P1 & $\underline{\text { CTGGCT TCCAAGTCT TAGCAC }}$ \\
P2 & TTATTTTTTATTTCAGTGGCTTCCAAGTCTTAGTAT \\
P3 & GGATTTGAATTCGGGCGTCT \\
\hline
\end{tabular}

Underlined bases indicate the introduced mismatches. 
The PCR reaction was carried out in a total volume of $30 \mu \mathrm{l}$, containing 100-200 $\mathrm{ng}$ of genomic DNA as template, $0.4 \mu \mathrm{M}$ of each primer, $0.2 \mathrm{mM}$ of each dNTP, $2.3 \mathrm{mM}$ of $\mathrm{MgCl} 2$, Taq buffer (20mM Tris- $\mathrm{HCl} \mathrm{pH} 8.4,50 \mathrm{mM} \mathrm{KCl})$, and $1 \mathrm{U}$ of a HotStart Taq DNA polymerase (JumpStart $^{\mathrm{TM}}$ Taq DNA Polymerase, SigmaAldrich, USA). PCR amplification was carried out in a MasterCycler ${ }^{\circledR}$ thermal cycler (Eppendorf, Germany), with an initial denaturation at $94{ }^{\circ} \mathrm{C}$ for $5 \mathrm{~min}$, followed by 33 cycles of $94{ }^{\circ} \mathrm{C}$ for $30 \mathrm{~s}, 60{ }^{\circ} \mathrm{C}$ for $30 \mathrm{~s}$ and $72{ }^{\circ} \mathrm{C}$ for $10 \mathrm{~s}$, and a final extension at $72{ }^{\circ} \mathrm{C}$ for $5 \mathrm{~min}$. Six microliter of loading buffer was added to the PCR reaction volume and a $20-30 \mu \mathrm{L}$ aliquot was subjected to agarose gel (3\%) electrophoresis.

\subsection{Validation of genotypes assigned by tri- primer ARMS-PCR}

Genotype assignment was validated for 10 samples using the PCR-RFLP method which was carried out as previously reported [17]. The PCR product was digested with HinfI restriction enzyme (Fermentas, Lithuania) according to the manufacturer's directions. The digested PCR fragments were separated on $2 \%$ agarose gels. Genotypes were scored as homozygous for the C allele if the $172 \mathrm{bp}$ PCR fragment after digestion remained uncut, or homozygous for the $\mathrm{T}$ allele if two bands were observed following enzyme digestion (131 and $41 \mathrm{bp}$ ). Gels with three DNA fragments $(172,131$, and $41 \mathrm{bp})$ were scored as heterozygotes.

\section{Results and discussion}

\subsection{Tri-primer ARMS-PCR analysis}

The procedure rendered 2 bands in heterozygotes (75 and $90 \mathrm{bp}$ ), and a single band at $75 \mathrm{bp}$ or $90 \mathrm{bp}$ in CC or TT homozygotes, respectively (Fig. 1b).

PCR components concentrations and reaction conditions were thoroughly optimized in order to ensure high specificity and sensitivity. The introduction of a mismatch at the $3^{\text {rd }}$ in the $3^{\prime}$ termini of the specific primers and the use of a high melting temperature ensured maximum specificity.
A second mismatch at the $5^{\prime}$ ultimate nucleotide of the short $\mathrm{C}$ allele specific primer greatly reduced the addition of a single-stranded 5 '-tail to the 75 bp fragments through megapriming which can be a result of the annealing of the $\mathrm{T}$ allele specific primer, producing an artifact that interferes with separation by gel electrophoresis.

Limiting the distance between the forward primers and the reverse primer, and the addition of a long AT-rich 5'-tail to the $\mathrm{T}$ allele specific primer were shown to be effective approaches in order to facilitate the separation of the two specific amplicons within a reasonable amount of time by agarose gel electrophoresis.

The proposed method was validated by a PCR-RFLP method for 10 samples. There was a $100 \%$ accordance between both methods for genotype adscription.

The basis of ARMS is that oligonucleotides with a mismatched 3 '-residue do not function as primers in the PCR upon the use of a DNA polymerase without 3'-exonuclease activity. Classically, the technique requires that only the terminal 3'-nucleotide of a PCR primer be allele specific. Thus, the primer is synthesized in two forms: the wild form is refractory to PCR on mutant template DNA, and conversely. Then, two different PCR reactions must be performed to determine the zygosity of any sequence change [28].

In contrast to the most commonly used PCRRFLP method [17-19], the proposed method does not involve the time consuming incubation step with costly restriction enzymes, resulting in significant improvement in detection time and cost.

TaqMan and direct sequencing methods require costly reagents, dedicated instruments, and relatively high level of expertise [20,21]. On the contrary, the proposed method involves a simple PCR step followed by gel electrophoresis.

The PCR-CCTP [6, 22], which is similar to the tetra-primer ARMS-PCR [29], is a simple onestep method that does not involve the use of restriction enzymes. However, the proposed Triprimer method involves the use of only three primers and does not lead into the production of a third common non-indicative PCR amplicon, 
which can compete with the amplification of the indicative specific amplicons and/or lead into the production of false positive results, rendering the method more difficult to optimize, and harder to be applied for the simultaneous detection of multiple SNPs in a single PCR reaction.

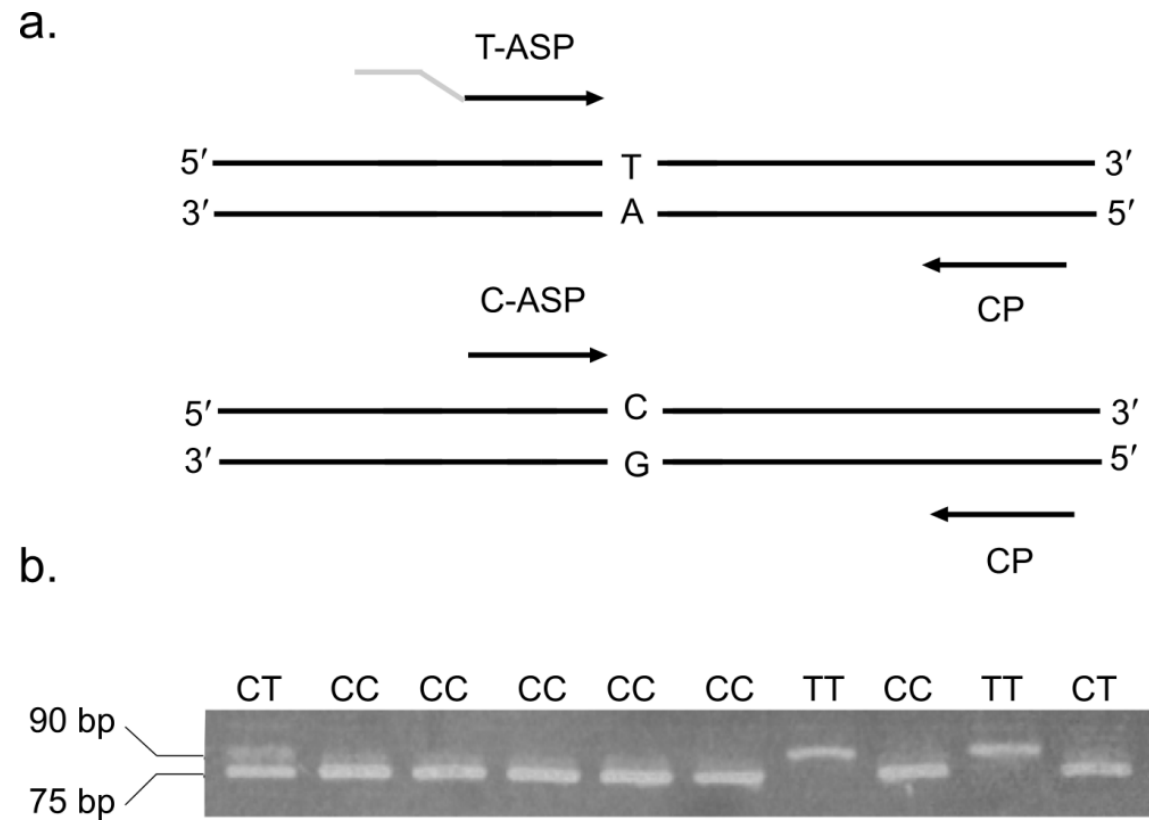

Fig. 1 a. The principle of Tri-primer ARMS. The T allele specific primer (T-ASP) is attached to a discriminative long 5 '- tail amplifying a $90 \mathrm{bp}$ fragment in conjunction with the common primer $(\mathrm{CP})$. The $\mathrm{C}$ allele specific primer amplifies a $75 \mathrm{bp}$ fragment in conjunction with the common primer. b. Agarose gel electrophoretogram of C609T NQO1 polymorphism detection in 10 samples. The presence of a single $90 \mathrm{bp}$ or $75 \mathrm{bp}$ band indicates a TT homozygous or $\mathrm{CC}$ homozygous, respectively. The presence of the two aforementioned bands indicates a CT heterozygous.

\subsection{Genotype distribution of C609T polymorphism in a sample population from Syria}

A total of 71 healthy subjects living in Aleppo, Syria, were genotyped for the C609T polymorphism, which is known to be differentially distributed among different ethnic groups. Among the 71 subjects genotyped, $54(76 \%)$ were found to be homozygous for the $\mathrm{C}$ allele, $2(2.8 \%)$ were found to be homozygous for the $\mathrm{T}$ allele, and 15 $(21.2 \%)$ were found to be heterozygous. Allele frequencies were found to be $87 \%$ and $13 \%$ for the $\mathrm{T}$ allele and $\mathrm{C}$ allele, respectively. The genotype distribution was found to be in Hardy-Weinberg equilibrium $(\chi 2=0.56 ; \mathrm{df}=1 ; \mathrm{p}=0.76)$.

The genotype distribution of the C609T polymorphism in the sample population is representative of the Arab population which is a distinct ethnic group. The obtained genotype distribution is close to that previously reported for the Caucasian, Hindu and African populations [23-26], and different from that previously reported for the East Asian and Hispanic populations $[6,17,27]$, where the $\mathrm{T}$ allele is nearly as common as the $\mathrm{C}$ allele (Fig. 2). The genotype distribution and allele frequencies obtained can potentially serve as control values for multiple case-control association studies involving Arab populations.

In conclusion, a rapid, simple, and costeffective method has been described for the detection of C609T, based on an uncommon variation of the ARMS method that simplifies detection and facilitates multiplexing. 


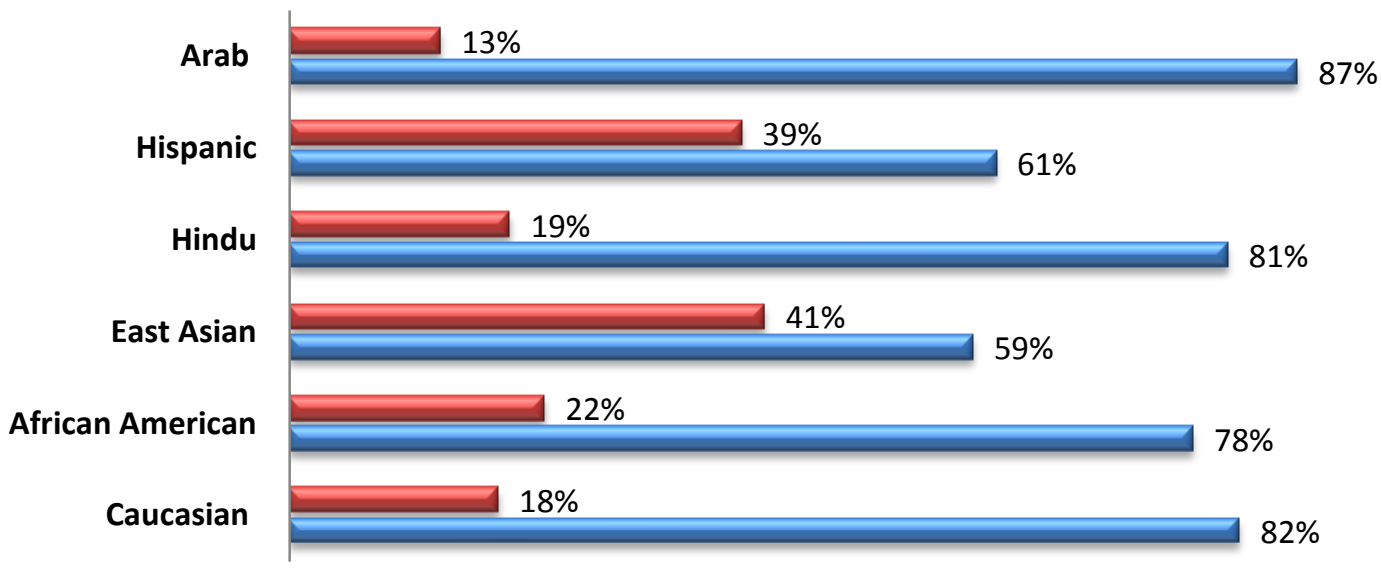

Fig 2. A comparison chart of C609T allele frequencies between different ethnic groups (Arab (present study), Hispanic [27], Hindu [25], East Asian [17], African American [26], and Caucasian[23]).

\section{References}

[1] Kuehl, B. L., J. W. Paterson, et al. (1995). "Presence of a heterozygous substitution and its relationship to DT-diaphorase activity." $\mathrm{Br}$ J Cancer 72(3): 555-561. Doi:10.1038/bjc.1995.373.

[2] Anwar, A., D. Siegel, et al. (2002). "Interaction of the molecular chaperone Hsp70 with human $\mathrm{NAD}(\mathrm{P}) \mathrm{H}$ :quinone oxidoreductase 1." J Biol Chem 277(16): 14060-14067. Doi: 10.1074/jbc.M111576200.

[3] Traver, R. D., T. Horikoshi, et al. (1992). "NAD(P)H:quinone oxidoreductase gene expression in human colon carcinoma cells: characterization of a mutation which modulates DT-diaphorase activity and mitomycin sensitivity." Cancer Res 52(4): 797-802.

[4] Lewis, S. J., N. M. Cherry, et al. (2001). "Polymorphisms in the $\mathrm{NAD}(\mathrm{P}) \mathrm{H}$ : quinone oxidoreductase gene and small cell lung cancer risk in a UK population." Lung Cancer 34(2): 177-183.. $\quad$ DOI: $10.1016 / S 0169-$ 5002(01)00243-4.

[5] Menzel, H. J., J. Sarmanova, et al. (2004). "Association of NQO1 polymorphism with spontaneous breast cancer in two independent populations." Br J Cancer 90(10): 1989-1994. doi: 10.1038/sj.bjc.6601779.

[6] Hamajima, N., K. Matsuo, et al. (2002). "NAD(P)H: quinone oxidoreductase 1 (NQO1) C609T polymorphism and the risk of eight cancers for Japanese." Int J Clin Oncol 7(2): 103-108.

[7] Niwa, Y., K. Hirose, et al. (2005). "Association of the $\mathrm{NAD}(\mathrm{P}) \mathrm{H}$ : quinone oxidoreductase C609T polymorphism and the risk of cervical cancer in Japanese subjects." Gynecologic Oncology 96(2): 423-429. doi:10.1016/j.ygyno.2004.10.015

[8] di Martino, E., L. J. Hardie, et al. (2007). "The $\mathrm{NAD}(\mathrm{P}) \mathrm{H}$ :quinone oxidoreductase I C609T polymorphism modifies the risk of Barrett esophagus and esophageal adenocarcinoma." Genetics in Medicine 9(6): 341-347. doi: 10.1097/GIM.0b013e3180654ccd

[9] Wang, B., F. Jin, et al. (2006). "Association analysis of $\mathrm{NAD}(\mathrm{P}) \mathrm{H}$ :quinone oxidoreductase gene $609 \mathrm{C} / \mathrm{T}$ polymorphism with Alzheimer's disease." Neuroscience Letters 409(3): 179181. doi:10.1016/j.neulet.2006.09.042.

[10] Okada, S., F. M. Farin, et al. (2005). "No associations between Parkinson's disease and polymorphisms of the quinone oxidoreductase (NQO1, NQO2) genes." Neuroscience Letters 375(3): 178-180. 
[11] Chi-Un, P., Y. Soo-Jung, et al. (2007). "Quinone oxidoreductase (NQO1) gene polymorphism may not confer a susceptibility to mood disorders." Psychiatry Research 153(1): 83-86.

[12] Chen, Y., Li, G., Yin, S., Xu, J., Ji, Z., Xiu, X., Liu, L., Ma, D., (2007). Genetic polymorphisms involved in toxicantmetabolizing enzymes and the risk of chronic benzene poisoning in Chinese occupationally exposed population. Xenobiotica 27, 103-112. doi:10.1080/00498250601001662.

[13] Rothman, N., Smith, M.T., Hayes, R.B., Traver, R.D., Hoener, B., Campleman, S., Li, G.L., Dosemeci, M., Linet, M., Zhang, L., Xi, L., Wacholder, S., Lu, W., Meyer, K.B., Titenko-Holland, N., Stewart, J.T., Yin, S., Ross, D., 1997. Benzene poisoning, a risk factor for hematological malignancy, is associated with the NQO1 $609 \mathrm{C} \rightarrow \mathrm{T}$ mutation and rapid fractional excretion of chlorzoxazone. Cancer Res. 57, 2839-2842.

[14] Wan, J., Shi, J., Guan, J., Ye, R., Gao, X., Liu, W., Hui, L., Cao, D., Jin, X., Hu, G., Xia, Z., (2002). Relation of genetic polymorphism of NQO1 and GSTT1 with risks of chronic benzene poisoning. Zhonghua Lao Dong Wei Sheng Zhi Ye Bing Za Zhi 20, 340-343.

[15] Wan, J., Shi, J., Hui, L.,Wu, D., Jin, X., Zhao, N., Huang,W., Xia, Z., Hu, G., (2002). Association of genetic polymorphisms in CYP2E1, MPO, NQO1, GSTM1, and GSTT1 genes with benzene poisoning. Environ. Health Perspect. 110, 1213-1218. doi:10.1289/ehp.021101213

[16] Ren, C., S. K. Park, et al. (2010). "Air Pollution and Homocysteine: More Evidence That Oxidative Stress-related Genes Modify Effects of Particulate Air Pollution." Epidemiology 21(2): 198-206 doi :110.1097/EDE.1090b1013e3181cc1098bfc.

[17] Zhang, J., W. A. Schulz, et al. (2003). "Association of $\mathrm{NAD}(\mathrm{P}) \mathrm{H}$ : quinone oxidoreductase 1 (NQO1) C609T polymorphism with esophageal squamous cell carcinoma in a German Caucasian and a northern Chinese population." Carcinogenesis 24(5): 905-909. doi: 10.1093/carcin/bgg019.
[18] Zhang, J.H., Li, Y., Wang, R., Geddert, H., Guo, W., Wen, D.G., Chen, Z.F., Wei, L.Z., Kuang, G., He, M., et al., (2003). NQO1 C609T polymorphism associated with esophageal cancer and gastric cardiac carcinoma in North China. World J.Gastroenterol. 9, 1390-1393.

[19] Begleiter A, Norman A, Leiteo D, Cabral T, Hewitt D, Pan S, et al. Role of NQO1 polymorphisms as risk factors for squamous cell carcinoma of the head and neck. Oral Oncol 2005; 41:927-33. doi: 10.1016/j.oraloncology.2005.05.004

[20] Han, S. J., E. S. Kang, et al. (2009). "The C609T variant of NQO1 is associated with carotid artery plaques in patients with type 2 diabetes." Molecular Genetics and Metabolism 97(1):85-90.doi:10.1016/j.ymgme.2009.01.012

[21] Shi, M. M., S. P. Myrand, et al. (1999). "High throughput genotyping for the detection of a single nucleotide polymorphism in NAD $(\mathrm{P}) \mathrm{H}$ quinone oxidoreductase (DT diaphorase) using TaqMan probes." Molecular Pathology 52(5): 295-299. doi:10.1136/mp.52.5.295

[22] Hamajima, N. (2001). "PCR-CTPP: a new genotyping technique in the era of genetic epidemiology." Expert Rev Mol Diagn 1(1): 119-123.

.[23] Smith MT, Wang Y, Kane E, et al (2001). Low NAD(P)H:quinine oxidoreductase 1 activity is associated with incrased risk of acute leukemia in adults. Blood, 97, 1422-6. DOI: 10.1182/blood-2001-12-0264.

[24] Krajinovic, M., Sinnett, H., Richer, C., Labuda, D. and Sinnett, D. (2002), Role of NQO1, MPO and CYP2E1 genetic polymorphisms in the susceptibility to childhood acute lymphoblastic leukemia. International Journal of Cancer, 97: 230-236. DOI: $10.1002 /$ ijc.1589.

[25] Parihar SS, Chauhan UK. The NQO1 allelic frequency in hindu population of central India varies from that of other Asian populations. Indian J Hum Genet 2010;16:133-7.

[26] Wiencke, J. K., M. R. Spitz, et al. (1997). "Lung cancer in Mexican-Americans and African-Americans is associated with the wildtype genotype of the $\mathrm{NAD}(\mathrm{P}) \mathrm{H}$ : quinone oxidoreductase polymorphism." Cancer 
Epidemiology Biomarkers \& Prevention 6(2): 87-92.

[27] Kelsey KT, Ross D, Traver RD, Christiani DC, Zuo ZF, Spitz MR, et al. Ethnic variation in the prevalence of a common $\mathrm{NAD}(\mathrm{P}) \mathrm{H}$ quinone oxidoreductase polymorphism and its implications for anticancer chemotherapy. $\mathrm{Br} \mathbf{J}$ Cancer 1997; 76:852-4.

[28] Newton CR, Graham A, Heptinstall LE, Powell SJ, Summers C, Kalsheker N, et al.
Analysis of any point mutation in DNA. The amplification refractory mutation system (ARMS). Nucleic Acids Res 1989;17:250316. doi: 10.1093/nar/17.7.2503

[29] Ye S, Dhillon S, Ke X, Collins AR, Day IN. An efficient procedure for genotyping single nucleotide polymorphisms. Nucleic Acids Res 2001;29:E88. doi:10.1234/12345678 